\title{
INVESTIGATING THE CAUSAL ASSOCIATION BETWEEN UNIONISM AND ORGANIZATIONAL EFFECTIVENESS
}

\author{
Kim S. Cameron
}

In an earlier study, a negative relationship was found between faculty unionism and organizational effectiveness in colleges and universities. No research, however, has ever investigated potential causality in this relationship, that is, whether ineffectiveness leads to unionism or whether unionism leads to ineffectiveness. This study relies on assessments of organizational effectiveness in a sample of 4-year institutions in 1976, 1980, and 1983 to investigate the potential causal directionality of these two factors. The results of the analyses suggest that ineffectiveness leads to unionism, but that once unionized, organizational effectiveness does not seem to improve.

Little is known about the impact of collective bargaining in higher education, and speculation and opinion still dominate the literature (see Baldridge et al., 1981; Gilmore, 1981; Wilson, 1983). A number of investigators have studied factors that seem to motivate the formation of unions (see Carr and Van Eyck, 1973; Duryea, Fisk, and Associates, 1973; Garbarino, 1975; Kemerer and Baldridge, 1975), but investigations of the effects of unionism have been few. Moreover, no study has investigated the cause-effect relationship between unionism and organizational effectiveness. Previous outcomes or effect studies have been limited mainly to individual-level factors and traditional trade union variables such as participation, grievances, compensation, and working conditions (see Baldridge et al., 1978; Bennett and Johnson, 1979; Birnbaum, 1974, 1976; Brown and Stone, 1977; Hedgepeth, 1974; Kemerer and Baldridge, 1975; Keaveny and Allen, 1979; Ladd and Lipset, 1978; Morgan and Kearney, 1977; Mortimer, 1975). Contradictory findings have been found regarding the impact of unions on these factors, and little longitudinal research had been done to help clarify the relationships. For

Kim S. Cameron, Graduate School of Business Administration and Center for the Study of Higher Education, The University of Michigan.
Research in Higher Education
(C) 1985 Agathon Press, Inc.
Vol. 23, No. 4 
example, Guthrie-Morse et al., (1981) found that under some conditions nonunion faculties have received higher compensation than union faculties, but under other conditions the reverse is true. Birnbaum (1980) summarized literature arguing that decreased participation and communication occur on unionized campuses, whereas Baldridge and Kemerer (1981) summarized literature arguing just the reverse. Shanker (1978), Cameron (1982), Lombardi (1979), and others found that the relative power of the faculty increases relative to administrators under unionized conditions. Richardson and Mortimer (1979), Baldridge et al. (1981), Baldridge and Tierney (1979), and others reported the opposite; that is, that administrator power increases relative to the faculty.

In addition to this ambiguity regarding individual-level factors, confusion and lack of clarity also are presented regarding the relationship between unionism and organizational-level factors. These variables have been included in research much less frequently than individual-level variables, although some studies have begun to appear. Kerr (1980) pointed out that "collective bargaining, in nearly all situations, has its origins more in antagonism than in affection, in hate than in love" (p. v). Consequently, the formation of unions is expected to affect the climate of colleges and universities and the processes of governance. For example, Wilson et al. (1983) found "significant changes" in governance, academic freedom, administrator and faculty attitudes, and performance when comparing pre- and postunion conditions. Moore (1981) reported major alterations in trust, standardization, centralization, and leadership style associated with unionism. Richardson and Mortimer (1978) found increases rigidity and decreased innovation in unionized schools (although they speculated that these conditions would decrease over time), and Baldridge et al. (1978) reported more formalization, standardization, and centralization of procedures when unionism was present. Gilmore (1981) reported changes from collegial to adversarial relationships among faculty and administrators and greater specialization of functions.

On the other hand, Birnbaum and Inman (1983) reported that no significant change occurred on the Institutional Functioning Inventory dimensions (including academic freedom, governance, administrator and faculty attitudes, leader style, morale, innovation, adaptability, etc.) between 1970 and 1980 for unionized versus nonunionized schools. Birnbaum and Inman (1983) concluded as follows:

Overall, therefore, recent research is building up a cumulative, consistent, and impressive picture of faculty collective bargaining as a process having surprisingly little impact upon many important aspects of institutional life. Neither those who have feared bargaining as a threat to traditional processes and values, nor those who have welcomed it as a universal corrective for continuing problems can find support for their positions in these studies. (pp. 9-10) 
Baldridge et al. (1981) reached a similar conclusion after a nationwide survey of faculty and administrators regarding unionism:

Administrators say unions have hurt a little, while union officials say unions have helped a little - but overall, the impression is that not much has changed. Faculty collective bargaining has not brought about the revolutionary changes its detractors and its supporters had predicted. (pp. 6, 46)

Differences in the findings of all these investigations may be due to variance in the definitions and measurements of unionism, to the different types of institutions used in each study, to the scarcity of longitudinal analyses, or to other factors embedded in the research designs. Regardless of the sources of confusion, however, it is clear that the topic of faculty unionism and its relationship to the functioning of institutions of higher education is a controversial and often emotional topic. Proponents and antagonists of unionism have argued their cases with vehemence.

\section{UNIONISM AND EFFECTIVENESS}

Several years ago research was conducted that contributed to this controversy surrounding the contributions and distractions of unionism in higher education (Cameron, 1982). That study investigated the relationship between faculty unionism and organizational effectiveness in colleges and universities and was based on cross-sectional data that precluded any causal conclusions from being drawn. In that investigation, unionized institutions scored lower than nonunionized institutions on eight of nine dimensions of organizational effectiveness. It was not clear, however, whether ineffective organizational performance preceded unionized faculties, whether unionization led to ineffective performance, or whether some kind of mutual causation was present between unionism and the dimensions of organizational effectiveness.

Some agitation resulted from the discovery of this negative relationship as proponents of and antagonists to unionism attributed opposite causal direction to the results. Opponents of unionism argued that the effectiveness of institutions is damaged by unionization of the faculty. After unions form, institutional effectiveness decreases, they argued. Proponents of unionism, on the other hand, suggested that ineffective institutional performance is a primary motivation for faculties to unionize. They argued that ineffectiveness causes unionism, therefore, and unions help restore higher levels of effectiveness after forming.

Unfortunately, no information has been available to support either point of view. Up to now, no study has been conducted to investigate associations between unionism and effectiveness using longitudinal data. In fact, Naples et al., (1978) summarized the current state of understanding regarding the 
effects of unionism on institutional performance this way:

The jury is still out on the issue of the impacts of collective bargaining. . . . Research is virtually non-existent and experiences are inconclusive. While it is difficult to conclude that faculty collective bargaining has damaged academic performance and vitality, the fact remains that a strong potential exists for this to occur. (pp. 95-96)

The major purpose of this paper is to investigate the causal relationships between the organizational effectiveness of colleges and universities and faculty unionism. Because the earlier study found that effectiveness scores are lower in unionized institutions than nonunionized institutions (Cameron, 1982), the intent of this current study is to address the question: Does ineffectiveness lead to unionization or does unionization lead to ineffectiveness?

\section{METHODOLOGY}

Identifying causality in the relationships between variables is most straightforward in experimental design. The application of treatment effects as well as other potential intervening variables can be controlled sufficiently that causal relationships between variables become clear (see Campbell and Stanley, 1963). The problem with studying the relationship between unionism and effectiveness, however, is that neither the treatment nor the potential extraneous causal factors can be controlled. That is, one cannot control when a faculty union will form, nor can one arbitrarily manipulate the performance of a college or university. In the earlier investigation, mean scores on effectiveness dimensions were compared between unionized and nonunionized institutions, and correlations between unionism and effectiveness were computed, but no causal conclusions could be drawn from either procedure.

\section{Cross-lagged Correlation Analysis}

In the absence of careful controls, therefore, as well as the absence of an expected theoretical relationship between unionism and effectiveness upon which path analysis (regression analysis) depends, the cross-lagged correlational technique is the most appropriate procedure to try to draw out patterns of causality (Campbell, 1963). Cross-lagged correlation is primarily an exploratory procedure designed to uncover "the preponderance of causation" (Crano et al., 1972) by eliminating alternative explanations owing to supuriousness (Kenny, 1975). Spuriousness refers to the condition where the relationship between two variables is not due to the effects of either, but to a 
third extraneous variable. The purpose of this analysis, therefore, is to identify which of two variables seems to be more powerful in affecting the other, while eliminating alternative causal explanations.

Kenny and Harackiewicz (1979) pointed out that cross-lagged analysis is largely an exploratory approach for generating interesting causal hypotheses. It is to be viewed more as an indicator of temporal precedence than as positive proof of causation. Because there is no a priori reason to expect unionism to lead to ineffectiveness or for ineffectiveness to lead to unionism, however, investigating this temporal precedence is a necessary first step in understanding the potential causal relationship between these two factors.

Cross-lagged correlational analysis requires at least two variables, each measured at two or more points in time. If one variable (e.g., unionism), measured at time 1 , is consistently followed by a change in the other variable (e.g., effectiveness), measured at time 2, and if the converse relationship is not true, then one can infer a causal association and direction. Correlations are computed between variable $A$ at time 1 with variable $B$ at time 2 , and also between variable $B$ at time 1 with variable $A$ at time 2 . It is rare that either of those two correlations is zero, because not only is it likely that some random correlation exists, but reciprocal causality is a common phenomenon among factors. However, if one correlation coefficient is significantly larger than another, a preponderance of causality can be assumed.

It should be emphasized that temporal precedence and causality are not precisely the same thing. One factor could conceivably appear before another factor on a consistent basis without influencing it causally. However, because it is impossible to manipulate either variable in this relationship, and because no prior information is available regarding the potential causal relationship between unionism and effectiveness, establishing temporal precedence is an informative first step in the causality debate. The crosslagged correlational technique is useful for establishing temporal precedence or directionality and for screening potentially spurious variables. Order precedence is a necessary condition for causality to be established, but it is not a sufficient condition.

Four different conditions must be met in cross-lagged analysis in order to eliminate the possibility of spurious correlations or uninterpreted results (Clegg et al., 1977; Kenny, 1975; Crano et al., 1972; Kenny and Harackiewicz, 1979). The first condition requires that the variables being assessed are reliable or that all measures of the same factor at one point in time are highly correlated. Second, synchronicity must be present in the two variables being assessed. This means that the two variables must be measured at the same point in time. Synchronicity can be inspected by observing the correlations between variable $A$ at time 1 and variable $B$ at time 1 , and the correlation between variable $A$ at time 2 and variable $B$ at time 2 . Both 
correlations are expected to be moderate to high (i.e., approximately . 3 or above). The third condition requires moderate stability or autocorrelation coefficients in at least one of the two variables. That is, when measuring variables at two points in time, some changes must occur in one of the variables between the two assessment points in order for a causal association to be determined. A variable that does not change cannot be influenced by a second variable that does not change (Clegg et al., 1977). The fourth condition, stationarity, means that the same causal relationship is present at the two points of measurement. The same causes of a variable exist at time 2 as existed at time 1 . This required condition implies that cross-lagged analysis is most appropriate when a causal relationship has stabilized, and it is less appropriate under turbulent or rapid change conditions when causality is not in equilibrium (Randolph, 1981). Stationarity can be tested by inspecting the patterns of cross-lag differentials and the synchronous correlations ( $r_{\mathrm{AlA} 2}$ and $\left.r_{\mathrm{B} 1 \mathrm{~B} 2}\right)$. Perfect stationarity exists when the synchronous coefficients do not change over time or they change by some constant, and when the pattern of cross-lagged differentials does not change over time.

The extent to which these four conditions - reliability, synchronicity, stability, and stationarity - are present in this investigation are explained in a later section.

\section{Instrument}

Organizational effectiveness was assessed in this investigation by an instrument first reported in Cameron (1978) and analyzed further in Cameron (1981, 1982, 1983, 1986). The instrument relies on judgments by internal dominant coalition members of the degree to which the organization possesses certain characteristics indicative of effective organizations. Nine valid and reliable dimensions of effectiveness are assessed by the instrument.

Internal consistency reliabilities are high for the nine dimensions, and a variance component analysis (Kavanagh et al., 1971) of a multitrait-multimethod matrix shows that the convergent and discriminant validities of these dimensions are good. Correlations with objective indicators of effectiveness also provide evidence for the external validity of the dimensions (see Cameron, in press). That is, the dimensions have been found to indicate characteristics of institutional performance, and they are not simply products of respondents' a priori attitudes. Statistical analyses also reveal that when rating the effectiveness of their institutions on the nine dimensions, faculty, administrator, and trustee judgments are essentially the same. No statistically significant differences are present.

The nine dimensions of effectiveness and their definitions are the following: 
1. Student educational satisfaction - The degree to which students are satisfied with their educational experiences at the institution

2. Student academic development-The degree of academic attainment, growth, and progress of students and the academic opportunities provided by the institution

3. Student career development-The degree of occupational development of students and the emphasis and opportunities for career development provided by the institution

4. Student personal development-The degree of nonacademic, noncareer development (e.g., cultural, social) and the emphasis and opportunities for personal development provided by the institution

5. Faculty and administrator employment satisfaction-The satisfaction of faculty members and administrators with their employment

6. Professional development and quality of the faculty - The degree of professional attainment and development of the faculty and the emphasis and opportunities for professional development provided by the institution

7. System openness and community interaction - The emphasis placed on and success in interacting with, adapting to, and service in the external environment

8. Ability to acquire resources-The ability of the institution to acquire resources such as good students and faculty, financial support, and so on

9. Organizational health-The vitality and benevolence of the internal processes in the institution, such as openness and trust, problem-solving adequacy, shared information

\section{Sample}

The effectiveness questionnaire was administered to respondents in a sample of 4-year colleges and universities in 1976, 1980, and 1983. The sample was selected originally in order to maximize heterogeneity on institutional characteristics such as urban-rural, public-private, large-small (although all schools are less than 12,000 undergraduate FTE), unionized-nonunionized, and representing all 4-year NCHEMS classes of institutions. Confidentiality was promised, so names of schools are not used in this paper. In 1976, 41 institutions participated; in 1980, 29 of those same institutions participated; and in 1983, 26 of the institutions participated. Eighteen of the schools were common to all three studies. The number of respondents was 1,317 in 1976, 1,240 in 1980, and 246 in 1983. Respondents in each study consisted of academic, financial, student affairs, and general administrators, faculty department heads, and members of boards of trustees. These respondents represent the internal dominant coalition in colleges and universities (see 
TABLE 1. Characteristics of the Institutions in the 1976, 1980, and 1983 Samples

\begin{tabular}{ccccc}
\hline Year & $\begin{array}{c}\text { Number of } \\
\text { Schools }\end{array}$ & $\begin{array}{c}\text { Number Public } \\
\text { and (Private) }\end{array}$ & $\begin{array}{c}\text { Number } \\
\text { Unionized }\end{array}$ & $\begin{array}{c}\text { Average } \\
\text { Enrollment }\end{array}$ \\
\hline 1976 & 41 & $17(24)$ & 18 & 4,894 \\
1980 & 29 & $11(18)$ & 12 & 4,200 \\
1983 & 26 & $13(13)$ & 13 & 4,232 \\
\hline
\end{tabular}

Cameron, 1978; Pennings and Goodman, 1977) in that they are the major decision makers in the institutions, they tend to have an overall institutional perspective rather than a narrow view of their school, they are normally charged with helping to make the institution function effectively, and they represent the major internal stakeholders in the institution. In each of the 3 years, approximately half the respondents were faculty members, around $40 \%$ were administrators, and the rest were trustees.

There is no way to tell if the same people completed the questionnaire each time.' Therefore, there is no reason to expect major respondent bias in the three separate questionnaire administrations. Institutional characteristics are listed in Table 1 for the sample in each of the 3 years.

\section{Procedures}

Questionnaires were administered three times instead of the two times required by cross-lagged analysis because there is no a priori time period that is appropriate for testing a potential causal association between unionism and effectiveness. Effects may occur in the short run, or a longer time may be required for them to appear. The design of this study makes it possible to investigate causal associations with time lags as close as 3 years or as long as 7 years. It is unlikely that significant changes would occur in the nine dimensions of effectiveness measured in this study in a year or two, and cross-lagged analysis is inappropriate in conditions of marked change or turbulence. Therefore, at least a 3-year time span was deemed appropriate between questionnaire administrations in order for effects to stabilize. The relative stability of any proposed causal relationships can be determined by using the longer time frame in connection with the shorter time frame (see Tsui and Karwan, 1983).

Mean scores were computed for each of the institutions on each of the nine dimensions of effectiveness (OE), and an overall mean score (i.e., an average of the nine scores) was also determined. These scores were correlated with two measures of unionism - the presence or absence of a union $\left(\mathrm{U}_{p}\right)$ and the number of years the union has been in existence at the school $\left(\mathrm{U}_{y}\right)$. 


\begin{tabular}{llr}
\hline & YEAR & \\
1976 & 1980 & 1983 \\
\hline
\end{tabular}
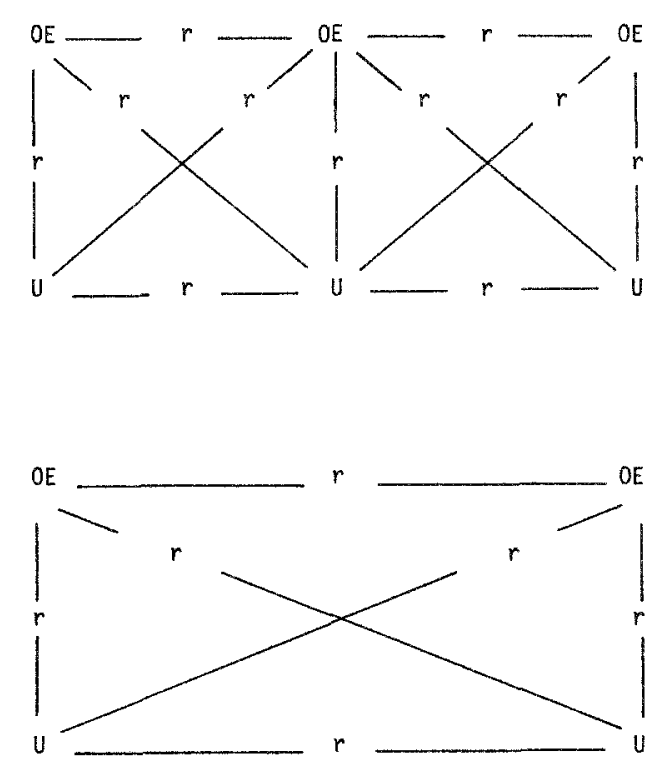

FIG. 1. Cross-lagged correlation models for investigating the relationship between effectiveness and unionism.

Consistent with the requirements of cross-lagged analysis, pair-wise correlations for each of the 3 years were analyzed, as shown in Figure 1.

\section{RESULTS}

A comparison of effectiveness scores on the nine dimensions for unionized versus nonunionized institutions reveals that in each of the three years, unionized institutions generally score lower than nonunionized institutions. For example, a comparison of the overall average effectiveness score for the unionized schools with the overall average effectiveness score for the nonunionized schools reveals that in 1976 nonunionized institutions scored significantly higher than unionized schools at the $p<.01$ level, in 1980 at the $p<.001$ level, and in 1983 at the $p<.01$ level.

Figure 2 plots the mean scores of the two groups for 1976, 1980, and 1983 and shows that unionized schools have lower scores on eight of nine dimensions in 1976, seven of nine dimensions in 1980, and seven of nine dimen- 

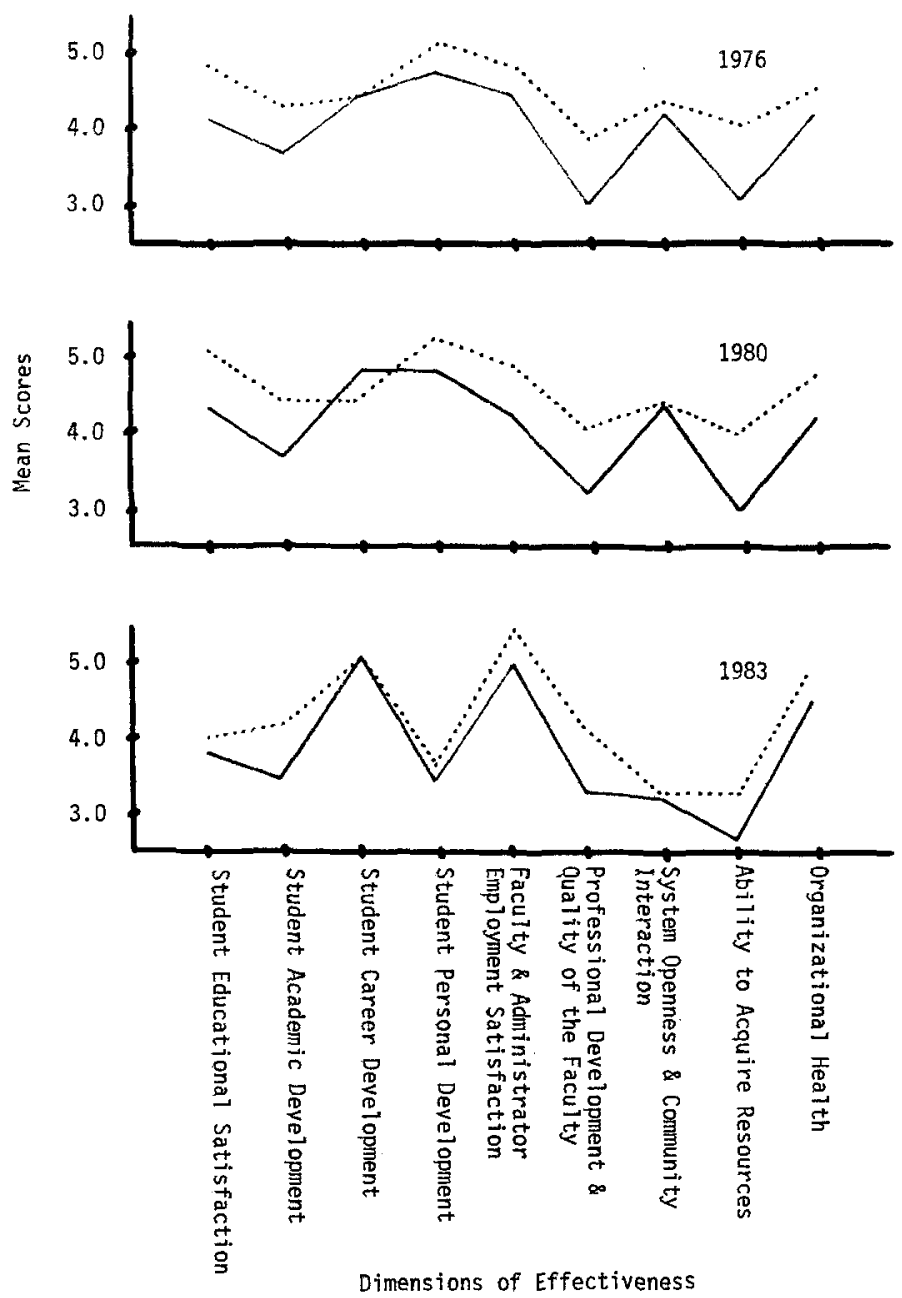

FIG. 2. A comparison of means on nine dimensions of effectiveness for unionized versus nonunionized institutions. Solid line, unionized; dotted line, nonunionized.

sions in 1983. Unionized schools scored higher on one dimension in 1980 and one dimension in 1983; there was one dimension in each year where scores were tied.

Tests for significant differences among means revealed that the three dimensions constituting the "academic domain" of the institutions (see Cameron, 1981) were significantly higher for nonunionized schools in each of the 3 years (i.e., nonunionized institutions scored higher on Student Academic Development, Professional Development and Quality of the Fac- 
ulty, and Ability to Acquire Resources). In addition, significant differences existed for five other dimensions in 1980 and for two other dimensions in $1983 .^{2}$

These analyses confirm earlier findings showing unionized schools to be less effective overall than nonunionized schools. However, the causal direction cannot be determined just by comparing mean scores. In order to determine which factor comes first, unionism or ineffectiveness, other analyses are required.

For example, the two institutions in the sample that formed unions between the first data collection effort in 1976 and the second data collection effort in 1980 were analyzed to see what changes occurred in their effectiveness scores. Both institutions experienced a substantial decrease in their overall mean effectiveness score between 1976 and the later data collection periods. However, because generalizing from a sample of two is tenuous, and because other institutions - both unionized and nonunionized-also experienced decreases, no conclusions can be drawn from those data. Instead, it is necessary to perform the cross-lagged correlation analysis for the two models shown in Figure 1.

Kenny and Harackiewicz (1979) indicated that interpretable results in cross-lagged analysis are most likely when the four conditions discussed earlier are present (i.e., reliability, synchronicity, stability, and stationarity) along with a large sample size. Large sample size is required because of the relatively small differences likely in cross-lagged correlations. "It is our expectation that even a strong causal effect may produce only a small crosslagged difference like .05" (Kenny and Harackiewicz, 1979, p. 374). A sample size of 2,006 is necessary for the .05 cross-lag differential to be significant at the .05 level using the Pearson and Filon test (Peters and Van Voorhis, 1940); a sample size of 488 is required to detect a .10 difference; and a sample of 114 is necessary to detect a .20 difference.

Unfortunately, this study has a very small sample size for cross-lagged analysis ( $n=41$ in 1976, $n=29$ in 1980, and $n=26$ in 1983). Therefore, significant differences between correlation coefficients are not likely to emerge. A differential of at least .32 is necessary to be detected in a sample size of 41. Even if significant differences do not exist, however, hints about causal direction can still be obtained. That is, the causal association between unionization and organizational effectiveness is not likely to be independent of the influences of a variety of other factors, so an unconditional causal relationship is unlikely to emerge. The best that one can hope for is evidence of causal directionality, which is the intent of this study. This sample size is sufficient to produce that kind of result. Significant coefficients would merely reflect the strength of the relationship, not its direction. And it is direction of causality that is important in this investigation. 


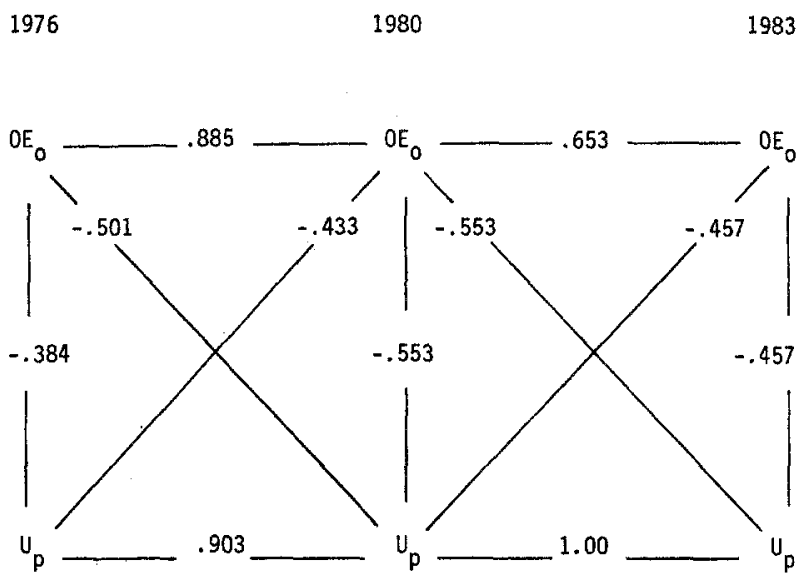

FIG. 3. Cross-lagged correlation analysis of effectiveness and the presence of a union, 1976-1980 and 1980-1983.

Before testing the cross-lag differentials, it was important to determine if the necessary four conditions were met for a cross-lagged analysis. Reliability of the nine effectiveness dimensions was confirmed for each of the 3 years. Internal consistency reliabilities ranged from .83 to .99 in $1976, .72$ to .92 in 1980 , and .70 to .90 in 1983 . Synchronicity was confirmed by the fact that both unionism and effectiveness were measured simultaneously in each of the three time periods, and the synchronous correlations are all sufficiently large to suggest that an a priori relationship exists between the two factors (see Kenny and Harackiewicz, 1979). Stability was found to be high among the variables. That is, the autocorrelations (e.g., $r_{0 \mathrm{OE} 760 \mathrm{E} 80}$ ) are high, suggesting that little change occurred between 1976 and subsequent years in unionism or effectiveness scores. On the other hand, inspection of the mean effectiveness scores for each institution in each year reveals a statistically significant change in 19 of the schools (differential $\geq .32$ ) between 1976 and 1983. Therefore, sufficient change in effectiveness scores is assumed for a meaningful cross-lagged analysis. Stationarity was tested by examining the cross-lag differentials to see if a change in pattern emerges (i.e., a dramatic change in magnitude or in the signs of the coefficients) suggesting a different causal relationship at different points in time. A consistent pattern was found. A more rigorous test of stationarity was performed by correcting the synchronous correlations for attenuation (see Kenny, 1975), and then comparing their differentials. No significant differences were found for any of the corrected synchronous correlations, suggesting that stationarity was acceptable.

With the four conditions met satisfactorily, it became possible to examine 


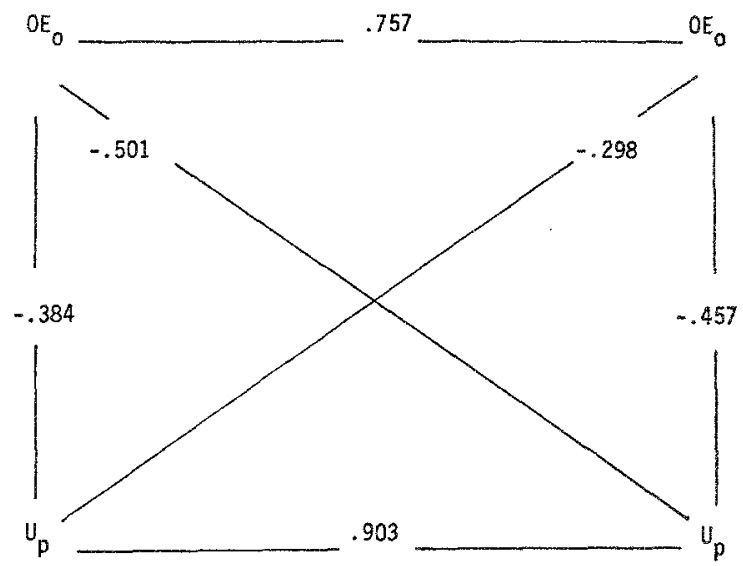

FIG. 4. Cross-lagged correlation analysis of effectiveness and the presence of a union, 1976-1983.

the cross-lagged correlations to determine the preponderance of directionality. Only four sets of the cross-lags are discussed here-those dealing with overall mean effectiveness scores correlated with the presence of a union $\left(\mathrm{U}_{p}\right)$ and with years of unionization $\left(\mathrm{U}_{y}\right)$. Cross-lagged correlations for each of the nine separate dimensions of effectiveness were computed and analyzed but since the results of those comparisons were largely consistent with the overall mean score patterns, and because a discussion of each dimension would be excessively lengthy (i.e., 252 correlation coefficients), they are not included in this paper.

Figure 3 shows the correlations of institutions' overall effectiveness scores with the presence of a union in those schools. The differential in cross-lags between 1976 and 1980 is $.068(p<.3)$, and between 1980 and 1983 it is .096 $(p<.3) .^{3}$ Neither differential is statistically significant at the traditional $p<.05$ level, but the preponderance of directionality is clearly low effectiveness leading to unionism for both time periods. Between 1980 and 1983 the differential is greater than in the earlier time period (1976-1980), suggesting that the causal direction is more pronounced. Figure 4 shows the correlations over the entire study period, 1976 to 1983, and indicates that the differential is greater (i.e., .203 $p<.2$ ) than in either shorter time span.

The emergence of a stronger causal association as the time lag becomes longer and more recent (i.e., 1980 to 1983) may suggest that the actual causal lag is closer to 7 years than to 3 years (i.e., ineffectiveness must be present for a longer time in order for it to motivate unionization) or that ineffective- 


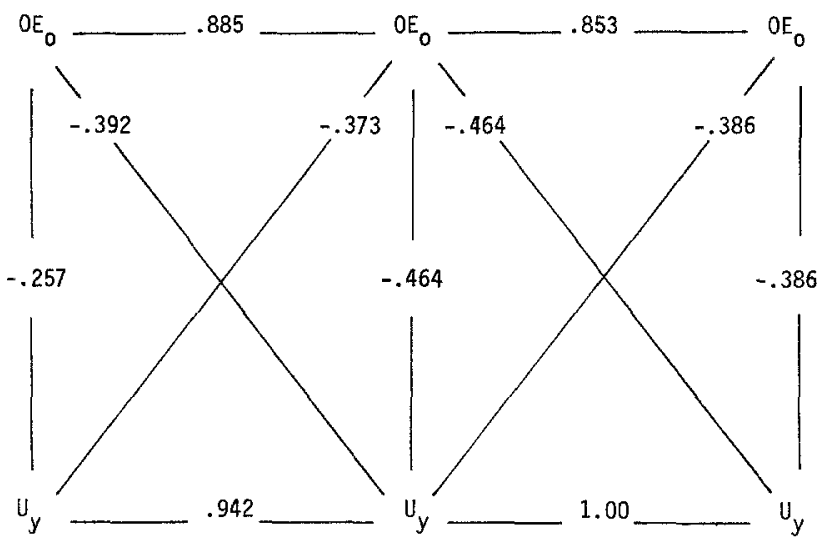

FIG. 5. Cross-lagged correlation analysis of effectiveness and years of unionism in institutions, 1976-1980 and 1980-1983.

ness has increased in importance over time as a motivating cause of unionization. The greatest growth in faculty unionism occurred in the mid-1970s, but there has been a marked slowing of union formation in recent years (Birnbaum, 1980; Cameron, 1982). Other factors than ineffectiveness (e.g., enabling legislation, economic factors, union organizing campaigns) most likely accounted for the occurrence of much collective bargaining in its first 10 years (1969-1979), but more recently, ineffectiveness may have become a more important factor.

Some light is shed on this association by analyzing the correlations between overall effectiveness $\left(\mathrm{OE}_{o}\right)$ and the years a union has been present on a campus $\left(\mathrm{U}_{y}\right)$. Union age for institutions in this study ranged from 0 to 13 years. Figure 5 presents the correlation results for 1976-1980 and 1980-1983, and Figure 6 presents the 1976-1983 time period.

Again, differentials are not large enough to be statistically significant (probabilities are $p<.3$ in two differentials and $p<.4$ in another), but the relative magnitudes of the coefficients are consistent with the previous interpretation; that is, continued ineffectiveness appears to be causally associated with the long-term presence of a union. What is of more interest, however; is a comparison of the differentials in 1976-1980 with those in 1980-1983. This analysis suggests that effectiveness doesn't improve over time in unionized schools. Instead, ineffectiveness continues to be associated with the presence of unionism over the years even when no new unions are formed (i.e., no new unions were formed in the sample between 1980 and 
$1976 \quad 1983$

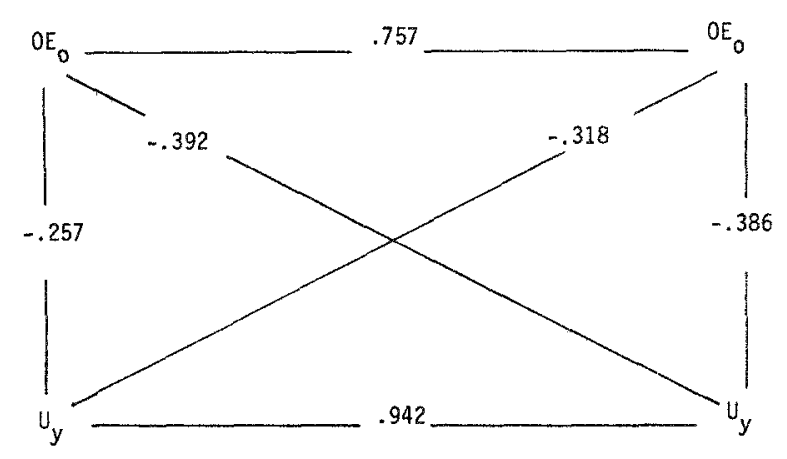

FIG. 6. Cross-lagged correlation analysis of effectiveness and years of unionism in institutions, 1976-1983.

1983). The directionality of causation remains ineffectiveness leading to unionism for both time periods, and this increasing negative correlation over time suggests that effectiveness in unionized institutions does not improve after unionization.

Another way to investigate whether or not effectiveness improves after unions are formed in institutions is to analyze the mean effectiveness scores of three groups of schools for each of the 3 years: (1) the nonunionized schools; (2) a group that had been unionized 2 or fewer years in 1976, 5 or fewer in 1980, and 8 or fewer in 1983 (designated "new unions"); and (3) a group that had been unionized 3 or more years in 1976, 7 or more in 1980, and 10 or more in 1983 (designated "old unions"). Figure 7 plots the mean scores for each group across each of the 3 years.

Overall effectiveness increased substantially for nonunionized institutions between 1976 and 1980, but returned in 1983 to the 1976 levels. The two unionized groups were equal and relatively stable in effectiveness in 1976 and 1980 , but were lower and substantially different in 1983. Institutions with old faculty unions decreased in effectiveness relative to new union schools. In 1976 and 1980, schools with old unions were approximately equal in effectiveness to the newly unionized schools. But by 1983, effectiveness in old union schools was substantially lower. Old union schools declined relative to the nonunionized group in 1980 and then remained approximately the same amount lower in $1983 .{ }^{4}$

This finding suggests that whereas the causal directionality is clearly ineffectiveness leading to unionism rather than the reverse, effectiveness does not increase as unions continue to exist on campuses, although it does not get much worse relative to nonunionized schools over time. 


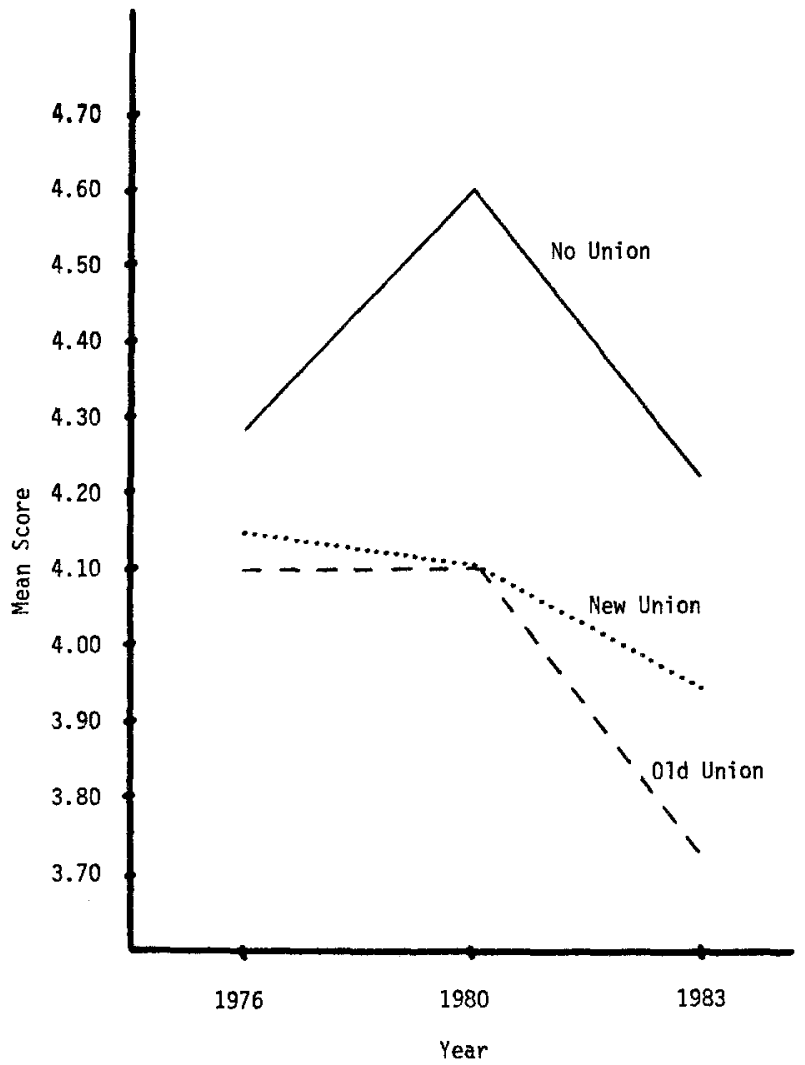

FIG. 7. A comparison of the overall effectiveness of institutions without a union, with a new union, and with an old union in three separate years.

\section{Potential Spuriousness}

One purpose of cross-lagged correlation analysis is to eliminate spuriousness as an explanation, that is, to determine if variables other than the ones being analyzed are the true causal factors. In this study it is important to know if a third variable causes both unionism and ineffectiveness. If so, focusing on those two factors alone is misleading. Because the differentials are not statistically significant in this study, it is still possible that a third more powerful variable accounts for the relationship between unionism and ineffectiveness. Birnbaum $(1980,1983)$ suggested that environmental changes cause both unionism and ineffectiveness, and therefore the directionality being investigated here may be misleading. Birnbaum (1983) stated:

I would suggest that it is not ineffectiveness that leads to unionization, but rather 
$\begin{array}{ll}1976 & 1980\end{array}$
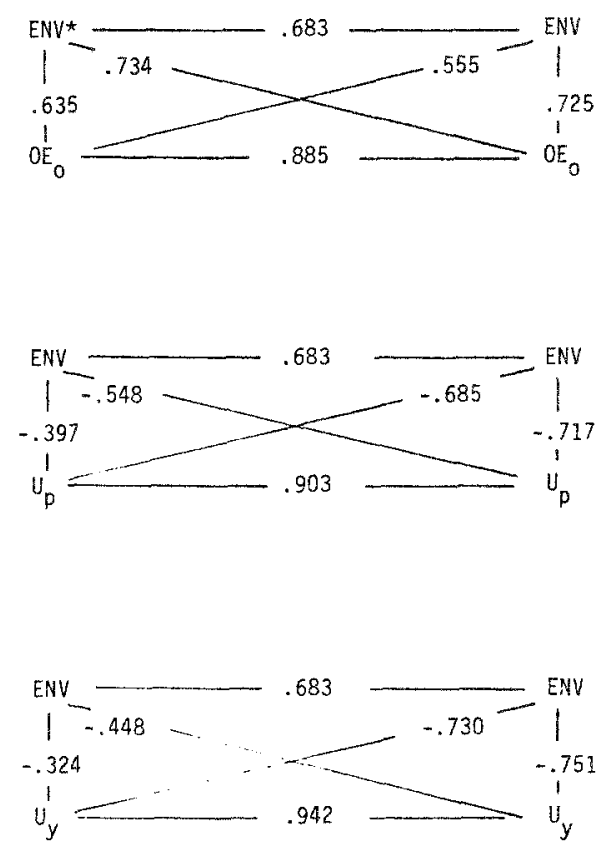

FIG. 8. Cross-lagged correlation analysis of the external environment (ENV) and effectiveness, years of unionism, and presence of a union, 1976 and 1980 . ${ }^{*}$ High scores on this variable indicate a supportive environment that fosters feelings of powerfulness. Low scores indicate a controlling environment that fosters feelings of powerlessness.

the environmental changes (primarily increased state control) that leads to powerlessness that causes unionization. It is this powerlessness that in turn causes both ineffectiveness and unionization.

Fortunately, a test of Birnbaum's proposition is possible with data collected from these institutions. In 1976 and 1980 (but not in 1983), respondents provided ratings of the extent to which the external environment was perceived as overcontrolling, nonsupportive, powerful, regulating, and hostile. That is, they rated the relative degree of powerlessness of the institution in relation to its external environment. A variable was constructed that measured the extent to which the external environment fostered feelings of powerlessness as opposed to feelings of discretion and powerfulness. Figure 8 summarizes the results. The top figure suggests that a supportive environment (i.e., one that supports discretion and powerfulness) leads to organiza- 
tional effectiveness. In the bottom two figures, however, the causal directionality is reversed. They suggest that unionism leads to perceptions of a nonsupportive environment (i.e., one that fosters feelings of powerlessness). The conclusion that emerges, therefore, is that the environment does not take temporal precedence over either ineffectiveness or unionization. Rather the hypothesized causal model that results from these analyses leads from a supportive environment to effectiveness and from unionization to a nonsupportive, controlling environment. Birnbaum's proposition is thus not supported.

This is not to suggest, of course, that no other factors exist that cause both ineffectiveness and unionism to occur. Spuriousness of some unknown variable may have influence on both factors. On the other hand, because of the consistency of the signs of the several correlations being considered (no aberrations in the pattern occurred), and because of the increased strength of the 7-year differential, there is reason to believe that the ineffectivenessunionism relationship has causal connections.

\section{DISCUSSION AND IMPLICATIONS}

The major finding of this investigation is that institutional ineffectiveness appears to lead to the formation of unions and that, over time, unionism does not have a positive influence on an institution's effectiveness. The statistical relationships are not significant in the cross-lagged differentials, but significance is not to be expected in cross-lagged analyses without every large sample sizes. And when analyzing the institution as a unit of analysis, it is highly unlikely that significance at the traditional $p<.05$ level will be achieved. There simply are not enough unionized campuses in the United States to create a sufficiently large sample size. What should be emphasized, however, is that many correlations are of interest simultaneously in these analyses, and the consistent agreement in directionality that emerges from the coefficients provides evidence that temporal precedence or a potential causal relationship exists. Not a single exception occurs in the pattern of correlations. The major caution, of course, is that lack of significance leads to an increased risk of Type II errors in interpreting the data.

This proposed relationship between organizational effectiveness and unionism also seems reasonable because of its consistency with previous research on effectiveness and with what is known about the motivations for and consequences of unionism. In the remainder of this section, some of that evidence is discussed in an attempt to explain why this relationship (i.e., ineffectiveness $\rightarrow$ unionism $\rightarrow$ ineffectiveness) may exist. Implications for both administrators and researchers in higher education are presented at the conclusion. 


\section{Potential Causal Explanations}

Colleges and universities are composed of at least two separate communities - the campus community and the disciplinary community (Alpert, 1983). The campus community entails administrative and organizational activities. College and university administrators largely control and govern that community. The disciplinary community entails scholarly contribution and professionalism, and it is controlled and governed mainly by professional associations and peer review. Unionization is more likely to occur in institutions where the disciplinary community is weak and where energies and loyalties are more closely associated with the campus community. In highly visible research universities, the disciplinary community is often so strong that it is possible for faculty to feel very little involvement and loyalty for the campus community (i.e., the institution, per se) and to attach their loyalties to the profession. When the organizational effectiveness of the campus community decreases or is threatened, collective action is a reasonable response in institutions without a strong disciplinary community. That is, when the campus community is the almost exclusive source of rewards and recognition for faculty contributions (i.e., when faculty have to rely on administrators for their incentive structures), and when the effectiveness of that campus community is threatened (e.g., when desirable incentives are not available), unionization may be the selected alternative for trying to preserve effectiveness. Unionization is less likely in institutions where rewards and recognition are provided by external professional groups and where loyalty to the campus community is more limited. (This helps explain why no institution that is a member of the $\mathrm{AAU}$ - major research universities - is currently unionized.)

Thus, as faculty perceive the institution to be ineffective or decreasing in effectiveness, unionism may emerge as a way to consolidate efforts and mobilize collective influence to improve campus effectiveness (see Staw and Szwajkowski, 1975; Child, 1972; Thompson, 1967). Coalition formation in order to protect some portion of the campus community is a rational response (March and Simon, 1958). This is consistent with the conclusion that ineffectiveness leads to unionism.

The second part of the conclusion, that unionism does not lead to improved effectiveness, is consistent with earlier research on unionism and effectiveness. That research found that unionized institutions exist in a less munificent external environment (i.e., fewer resources available) and that they have a lower ability to extract resources (including financial, academic, and symbolic resources) from those environments (Cameron, 1982). Both of these factors are associated with increasing effectiveness over time in colleges and universities (Cameron, in press). That is, schools that improve in 
overall organizational effectiveness over time are generally those that acquire needed resources from a relatively munificent environment. The formation of a union, which often leads to increased centralization and formalization, is unlikely to be influential in affecting conditions in the external environment or in improving institution-environment relations. Centralization restricts communication flows and boundary-spanning activities needed to influence the external environment. Flexibility and adaptability, which generally are required to acquire external resources, may suffer in unionized conditions. The energy of faculty leadership and administrators is often focused mostly on internal concerns and bargaining relationships under unionized conditions (Garbarino, 1975), so increased effectiveness may be unlikely to occur.

Under conditions of financial or enrollment stress, when environmental turbulence is especially acute, the most effective institutions are those whose administrators focus more on environmental relations than on internal concerns. Proactivity takes precedence over reactivity in these schools, and institutions are flexible enough to take quick decisive action (see Chaffee, 1984; Cameron, in press). In unionized institutions, quick decision making and decisive action are more difficult because of the multiple special interest groups needing to be satisfied and to grant approval. Turf protection, politics, and decision making through bargaining are common, (see Baldridge et al., 1981; Garbarino, 1975; Richardson and Mortimer, 1978). Having organizational effectiveness scores remain low, therefore, is not a surprising outcome, since the dynamics of collective bargaining may inhibit characteristics of high effectiveness from being achieved. The dimensions of effectiveness constituting the academic domain, in particular, appear to suffer as a result of the emphasis on trade union issues and adversarial relationships (Trow, 1975).

\section{Implications for Administrators}

Assuming that the major conclusion of this study has validity, three practical implications of this research can be identified for administrators in institutions of higher education. First, because the negative association between effectiveness and unionism is greatest in the academic domain, administrators may want to pay particular attention to possible erosion in this core set of activities. When energies become focused on legalistic issues and adversarial relations, a strong possibility exists for scholarship, collaboration, and personal development to be ignored, particularly as it relates to teaching and research. Consideration might be given to incentive systems and formalized programs to ensure that the academic domain of the institution is not neglected, especially in the early stages of unionization when 
there is most pressure to deflect attention away from scholarship, personal development, academic creativity, and scientific collaboration.

A second implication for administrators points out a paradox. Proactive, entrepreneurial, and externally focused strategies have been associated with improving effectiveness over time (Cameron, in press), yet these are among the conditions that are difficult to foster under unionized circumstances. Conservatism, protectionism, defensiveness, and reactivity are more typical of administrators faced with adversarial coalitions (Cameron and Chaffee, 1984). Therefore, consideration might be given to formalizing boundaryspanner roles, quality circles, strategic management teams, and other mechanisms oriented toward maintaining an open, anticipatory stance toward the environment and the future. Monitoring and planning for external contingencies is a prerequisite to preserving and enhancing effectiveness, so those activities should not be lost when administrators are pressed to respond continually to internal institutional concerns.

A third implication relates to the kind of relationship that is fostered among faculty and administrators on unionized campuses. The major issues in bargaining in higher education are almost always traditional trade union issues -i.e., wages, job security, and grievances - and adversarial relationships are not atypical of the interactions that occur relative to those questions. However, administrators may want to separate trade union issues from organization effectiveness issues and to foster a different kind of relationship with faculty with regard to enhancing institutional performance. Collaboration and collegiality need to be established among institutional members in at least some areas if the school is to do well in adapting to its environment. That relationship can be enhanced by partitioning the norms that govern faculty-administrator relationships. Rules of interaction should be different when the issue is academic excellence, for example, than when it is fringe benefits.

\section{Suggestions for Researchers}

In addition to practical implications, the results also have implications for future research on unionism and effectiveness. For example, the general conclusion of this paper helps explain one reason why some studies have concluded that significant negative consequences of unionism appear in institutions while other studies have concluded that no such consequences appear. When comparing nonunionized institutions with those that are unionized, significant differences have been demonstrated in their effectiveness. However, one reason for those differences may be explained, on the one hand, as the erosion of effectiveness in the institution and the subsequent unionization of the faculty. On the other hand, once unions are 
present in institutions, effectiveness does not change dramatically, but it continues to erode. Therefore, when comparing institutional conditions before and after unionism, significant differences may not occur because of the small impact of unionism on institutional functioning. When comparing unionized and nonunionized schools, however, significant differences do appear. This suggests that researchers should not only be conscious of the kinds of comparison groups used in studying the impacts of unionism, but that the causal relationships between unionism and institutional effectiveness should be more carefully and more broadly studied. Ethnographic case analyses may help illuminate this relationship as well as total population studies using all unionized institutions. In any case, longitudinal research should take priority over snapshot or cross-sectional analyses.

Acknowledgments. The research reported here was supported by a contract from the National Institute of Education (\#400-83-0009). The comments of Bob Birnbaum, Ken Mortimer, Dick Richardson, and the anonymous RHE reviewers were especially helpful during the preparation of this manuscript.

\section{NOTES}

1. In 1983, fewer respondents were sent a questionnaire than in the previous two studies. The average receiving a questionnaire in 1983 was 18 (approximately six administrators, six trustees, and six faculty members), as compared to approximately 50 in 1976 and 75 in 1980. Therefore, the smaller $n$ in 1983 could be a biasing factor in the results; but because all three samples included exactly the same positions at the institutions, there is no reason to believe the bias would be significant.

2. In 1980, significant differences existed for all dimensions except System Openness and Community Interaction. In 1983, significant differences existed for Organizational Health in addition to the three academic domain dimensions.

3. Point biserial correlations were computed in this analysis, since the unionism variable $\left(\mathrm{U}_{p}\right)$ was coded 1,0. Differentials are computed by subtracting $r_{0 \mathrm{E} 76 \mathrm{U} 80}$ from $r_{0 \mathrm{EE} 8 \mathrm{U} 76}$ and by subtracting $r_{0 \mathrm{~EB} 8 \mathrm{U} 83}$ from $r_{0 \mathrm{E} 83 \mathrm{U} 80}$.

4. No significant differences existed between the three groups in 1976, but nonunionized schools had significantly higher scores than unionized groups in $1980(p<.05)$ and the old union schools in $1983(p<.01)$. Significance was not reached in 1983 when comparing the means of the two unionized groups $(p<.2)$.

\section{REFERENCES}

Alpert, Daniel (1983). Performance and paralysis: The organizational context of the American research university. Working paper. Center for Advanced Study, University of Illinois.

Baldridge, J. Victor, Curtis, David V., Ecker, George, and Riley, Gary L. (1978). Policy Making and Effective Leadership. San Francisco: Jossey-Bass. 
Baldridge, J. Victor, and Tierney, Michael L. (1979). New Approaches to Management. San Francisco: Jossey-Bass.

Baldridge, J. Victor, Kemerer, Frank R., and Associates (1981). Assessing the Impact of Faculty Collective Bargaining. Washington, D.C.: American Association for Higher Education.

Bennett, J. T., and Johnson, M. J. (1979). Demographic Trends in Higher Education: Collective Bargaining and Forced Unionism? Los Angeles: International Institute for Economic Research.

Birnbaum, Robert (1974). Unionization and faculty compensation. Educational Record 55: 29-33.

Birnbaum, Robert (1976). Unionism and faculty compensation. Part 2. Educational Record 57: 116-118.

Birnbaum, Robert (1980). Creative Academic Bargaining: Managing Conflict in the Unionized College and University. New York: Teachers College Press.

Birnbaum, Robert (1983). Personal communication, 19 November.

Birnbaum, Robert, and Inham, Deborah (1983). The effect of faculty collective bargaining on campus climate. Paper presented at the Annual Meeting of the Association for the Study of Higher Education, Washington, D.C.

Brown, W. W., and Stone, C. C. (1977). Academic unions in higher education: Impacts on faculty salary, compensation, and promotions. Economic Inquiry 15 : 385-396.

Cameron, Kim S. (1978). Measuring organizational effectiveness in institutions of higher education. Administrative Science Quarterly 23: 604-632.

Cameron, Kim S. (1981). Domains of organizational effectiveness in colleges and universities. Academy of Management Journal 24: 25-47.

Cameron, Kim S. (1982). The relationship between faculty unionism and organizational effectiveness. Academy of Management Journal 25: 6-24.

Cameron, Kim S. (1983). An empirical investigation of the multiple constituencies model of organizational effectiveness. Working paper. Graduate School of Business Administration, University of Michigan.

Cameron, Kim S. (in press). A study of organizational effectiveness and its predictors. Management Science 32 (1986): to appear.

Cameron, Kim S., and Chaffee, E. E. (1984). The aftermath of decline. Working paper. Graduate School of Business Administration, University of Michigan.

Campbell, Donald T. (1963). From description to experimentation: Interpreting trends as quasi-experiments. In C. W. Harris (ed.), Problems in Measuring Change. Madison, Wis.: University of Wisconsin Press.

Campbell, Donald T., and Stanley, Julian C. (1963). Experimental and Quasi-Experimental Designs for Research. Chicago: Rand McNally.

Carr, Robert K., and VanEyck, Daniel K. (1973). Collective Bargaining Comes to the Campus. Washington, D.C.: American Council on Education.

Chaffee, E. E. (1984). Successful strategic management in small private colleges. Journal of Higher Education 55: 212-241.

Child, J. (1972). Organizational structure, environment, and performance: The role of strategic choice. Sociology 6: 2-21. 
Clegg, C. W., Jackson, P. R., and Wall, T. D. (1977). The potential of cross-lagged correlation analysis in field research. Journal of Occupational Psychology 50: $177-196$.

Crano, William D., Kenny, David A., and Campbell, Donald T. (1972), Does intelligence cause achievement?: A cross-lagged panel analysis. Journal of Educational Psychology 63: 258-275.

Duryea, E. D., Fisk, R. S., and Associates (1973). Faculty Unions and Collective Bargaining. San Francisco; Jossey-Bass.

Garbarino, Joseph W. (1975). Faculty Bargaining: Change and Conflict. New York: McGraw-Hill.

Gilmore, Carol B. (1981). The impact of faculty collective bargaining on the management of public higher educational institutions. Journal of Collective Negotiations 10: $145-152$.

Guthrie-Morse, Barbara, Leslie, Larry L., and $\mathrm{Hu}$, Teh-Wel (1981). Assessing the impact of faculty unions: The financial implication of collective bargaining. Journal of Higher Education 52: 237-255.

Hedgepeth, R. C. (1974). Consequences of collective bargaining in higher education. Journal of Higher Education 45: 691-705.

Kavanagh, M. J., MacKinney, A. C., and Wolins, L. (1971). Issues in managerial performance: Multitrait-multimethod analyses of ratings. Psychological Bulletin 75: $34-49$.

Keavenly, T. J., and Allen, R. E. (1979). The impact of unions on the structure of faculty compensation at public universities. Paper presented at the Academy of Management Meetings, Atlanta.

Kemerer, Frank R., and Baldridge, J. Victor (1975). Unions on Campus. San Francisco: Jossey-Bass.

Kenny, David A. (1975). Cross-lagged panel correlation: A test for spuriousness. Psychological Bulletin 82: 887-903.

Kenny, David A., and Harackiewski, Judith M. (1979). Cross-lagged panel correlation: Practice and promise. Journal of Applied Psychology 64: 372-379.

Kerr, Clark (1980). Introduction. In Robert Birnbaum (ed.), Creative Academic Bargaining. New York: Teachers College Press.

Ladd, Everett C., and Lipset, Seymour Martin (1978). Effects of unionism on higher education. In G. L. Riley and J. V. Baldridge (eds.), Governing Academic Organizations. Berkeley, Calif.: McCutchan.

Lombardi, John (1979). Changing administrative relations under collective bargaining. Junior College Resource Review. Los Angeles: ERIC Clearinghouse for Junior College Information.

March, J. G., and Simon, H. A. (1958). Organizations. Wiley.

Moore, Arnold J. (1981). Collective bargaining in higher education: Its impact on leadership styles, quality faculty, and programs. Presented at the Annual Meeting of the American Association of Colleges for Teacher Education, Detroit.

Morgan, D. R., and Kearney, R. C. (1977). Collective bargaining and faculty compensation. Sociology of Education 50: 28-39.

Mortimer, Kenneth P. (1975). Research Data on Tenure and Governance under Collective Bargaining. Washington, D.C.: ERIC Clearinghouse on Higher Education. 
Naples, Ceasar J., Caruthers, J. Kent, and Naples, Alexandra J. (1978). Faculty collective bargaining: Implications for academic performance and vitality. In Wayne R. Kirschling (ed.), Evaluating Faculty Performance and Vitality. San Francisco: Jossey-Bass.

Pennings, J. M., and Goodman, P. S. (1977). Toward a workable framework. In P. S. Goodman and J. M. Pennings (eds.), New Direction in Organizational Effectiveness. San Francisco: Jossey-Bass.

Peters, C. C., and Van Voohris, W. R. (1940). Statistical Procedures and Their Mathematical Bases. New York: McGraw-Hill.

Randolph, W. Alan (1981). Cross-lagged correlational analysis in dynamic settings. Journal of Applied Psychology 66: 431-436.

Richardson, Richard C., and Mortimer, Kenneth P. (1978). Collective bargaining and the redefinition of administrative roles. Education Records 59: 332-344.

Shanker, Albert (1978). Unions and the academic enterprise. Washington, D.C.: American Federation of Teachers.

Staw, B. M. and Szwajkowski (1975). The scarcity-munificence component of organizational environments and the commission of illegal acts. Administrative Science Quarterly 20: 345-359.

Thompson, J. D. (1967). Organizations in Action. New York: McGraw-Hill.

Tsui, Anne S., and Karwan, Kirk R. (1983). Managerial effectiveness and organizational performance: A test of causality. Presented at the Academy of Management meetings, Dallas.

Wilson, Bennie J., Holley, William H., and Martin, John S. (1983). Effects of faculty unions on administrators' attitudes toward issues in higher education. Journal of Collective Negotiations 12: 33-44.

Received August 31, 1985 